\title{
Influence of polyols on properties of bio-based polyurethanes
}

\author{
S GOPALAKRISHNAN* and T LINDA FERNANDO \\ Department of Pharmaceutical Chemistry, Manonmaniam Sundaranar University, Abishekapatti, \\ Tirunelveli 627 012, India
}

MS received 11 November 2010; revised 19 March 2011

\begin{abstract}
Polyurethane elastomers from cardanol-based polyol, polypropylene glycol (PPG-1200 and PPG-2000) and isophorone diisocyanate were prepared in the form of thin sheets. The sorption, mechanical and thermal properties were studied. The solubility parameter and molecular weight between crosslinks of polyurethane samples were calculated from swelling experiments. The swelling study of polyurethanes revealed that the sorption is found to decrease with an increase in chain length of PPG. The stress-strain data showed that the elastomers obtained using PPG-1200 gave the best mechanical properties. The thermal degradation of all the three elastomers starts almost at $270^{\circ} \mathrm{C}$, regardless of the PPG chain length. The value of activation energy of degradation calculated using the Broido method was in the range of $40-70 \mathrm{~kJ} / \mathrm{mol}$.
\end{abstract}

Keywords. Cardanol; isophorone diisocyanate; polypropylene glycol; polyurethane elastomers; solubility parameter; activation energy.

\section{Introduction}

Preparation of polymeric materials from renewable resources is of great significance economically and ecologically. Vegetable oils are becoming extremely important as renewable resources for the preparation of polyols required for the polyurethane industry. Among the vegetable oils, cardanol a meta-substituted phenol obtained (Kumar et al 2002) from cashew nut shell liquid (CNSL), stands out for the synthesis of polymeric products with speciality applications (Saunders and Frisch 1962; Ramesh et al 1991; Szycher 1999; Javni et al 2000; Saminathan and Pillai 2000; Sathiyalekshmi and Gopalakrishnan 2000; Mythili et al 2004; Klaus Friedrich et al 2005). Cardanol possesses good compatibility with polypropylene glycol (PPG) in all proportions so that PPG can be effectively blended with cardanol and its derivatives to obtain castable polyurethane elastomers with improved application properties. Polyurethanes are known for their industrial applications due to high strength resiliency and good resistance to abrasion. A favourable feature associated with polyurethane system is the ease with which the end property can be tailored with good control by mere adjustment in the formulation. A great number of factors such as extent of crosslinking, nature of polyol and diisocyanate and curing conditions are known to affect the properties of polyurethanes (Buist 1978; Lin and Biranowski Lorenz 1981; Bastids 1995; Rajalingan and Radhakrishnan 1995; Desai et al 1998).

In this study, we have used particularly a cycloaliphatic diisocyanate, because the polyurethanes prepared with this, possesses better colour retention and much superior exterior

\footnotetext{
*Author for correspondence (sgkmsu@yahoo.co.in)
}

durability than those with aromatic diisocyanates. Therefore, in the present study, we report the synthesis of polyurethanes by blending isophorone diisocyanate, cardanol-based synthesized polyol and commercial polyols PPG-1200 and PPG2000. The effect of molecular weight of polyols on physical, mechanical and thermal properties were studied.

The newly synthesized potential candidate polyurethanes with optimum mechanical and thermal properties are expected to find a special position in the biomedical field which includes the synthesis of artificial bile ducts, polyurethane vascular grafts, artificial heart valves and polyurethane trileaflet valves where interaction with the mimicking of soft tissue are required. Polyurethanes based on isophorone diisocyanate were expected to possess a lower coefficient of friction compared to those of silicone rubber and hence may be used in the synthesis of pacemaker lead insulation too.

\section{Experimental}

\subsection{Materials and methods}

Cardanol was procured from m/s Sathya Cashew Pvt. Ltd., Chennai. Formaldehyde ( $40 \%$ solution) for formylation and methanol for dissolving the catalyst were obtained from $\mathrm{m} / \mathrm{s}$ BDH Ltd. Sebacic acid and epichlorohydrin were received from m/s E Merck, Germany. Polypropylene glycols (PPG) with molecular weight 1200 and 2000 used in the study were purchased from Aldrich Chemicals (USA) and were dried over anhydrous $\mathrm{Na}_{2} \mathrm{SO}_{4}$ to remove traces of water. All the solvents used were of analytical grade and were further purified by distillation. Isophorone diisocyanate (IPDI) and the catalyst dibutyltin dilaurate (DBTDL) were received from Fluka Chemie (UK) and used as received. ${ }^{1} \mathrm{H}-\mathrm{NMR}$ 
spectrum of the synthesized polyol was recorded using the R $248 \times \mathrm{H} \times$ Hitachi $300 \mathrm{MHz}$ NMR spectrometer. Infrared spectrum was recorded in a JASCO FTIR spectrometer by $\mathrm{KBr}$ pellet method.

\subsection{Synthesis of cardanol-based polyol}

High ortho-multinuclear cardanol-formaldehyde resin was synthesized using cardanol: formaldehyde in the mole ratio 1:1 using sebacic acid as catalyst. Cardanol was taken in a three-necked round-bottomed flask equipped with a Liebig condenser, mechanical stirrer and thermometer. Formaldehyde and $1 \%$ sebacic acid catalyst in methanol $(2 \mathrm{ml})$ were added to the cardanol through a dropping funnel. The reaction was carried out at the temperature $120 \pm 5^{\circ} \mathrm{C}$ for $3 \mathrm{~h}$ and then at $150 \pm 5^{\circ} \mathrm{C}$ for $2 \mathrm{~h}$. The initial $\mathrm{pH}$ value of the mixture was lowered from 5 to 3 after the completion of the condensation. The resin was purified by dissolving in toluene and then by precipitating it with distilled water. Major fractions were collected and dried using a rotary evaporator under vacuum. The cardanol-formaldehyde resin was epoxidised using epichlorohydrin and the resulting epoxidized resin was hydrolyzed with dilute hydrochloric acid. The hydroxyalkylated resin thus formed was purified by washing with distilled water several times and then dried over vacuum at $80^{\circ} \mathrm{C}$ (scheme 1).

2.2a Spectral characterization of synthesized polyol: In the ${ }^{1} \mathrm{H}-\mathrm{NMR}$ spectra of the synthesized polyol (figure 1), peaks at $6 \cdot 60-7 \cdot 20 \delta$ are due to the aryl protons of benzene nuclei. The peak at $4.9-5.3 \delta$ is due to the methylene proton $\left(\mathrm{C}-\mathrm{CH}_{2}\right)$ of the long alkyl side chain originally present in cardanol. The peak at $3.60 \delta$ indicates methylene protons of ph- $\mathrm{CH}_{2}$-ph (the bridge between the phenyl rings). The peaks around 0.80 and $2.70 \delta$ are due to aliphatic side chain of cardanol. The small peak at $0.93 \delta$ represents the terminal methyl group of the chain. The analysis of peak height at $1.30 \delta$ reveals the presence of long chain containing more than five methylene groups in the side chain. All these spectral data indicate that the synthesized polyol was formed under experimental condition (figure 2).

In the case of IR spectral data of synthesized polyol, broad peak centering at $3427 \mathrm{~cm}^{-1}$ is due to $-\mathrm{OH}$ stretching. The peak at $914 \mathrm{~cm}^{-1}$ is due to substitution in benzene nuclei and the peak at $778 \mathrm{~cm}^{-1}$ is due to three adjacent hydrogen atoms in the benzene nuclei. The peaks at $720 \mathrm{~cm}^{-1}$ and $860 \mathrm{~cm}^{-1}$ indicate the ortho- and para-substitution, respectively at benzene nuclei. The peak at $1130 \mathrm{~cm}^{-1}$ indicates the presence of hydroxyalkyl groups in the polyols (figure 2). All the above spectral data confirm the formation of synthesized polyol.

\subsection{Synthesis of polyurethanes}

Castable polyurethane elastomer (PU-CP) was prepared by the reaction of cardanol-based synthesized polyol with isophorone diisocyanate and the catalyst DBTDL (0.01 wt.\% total charge) by maintaining the isocyanate index $(\mathrm{NCO} / \mathrm{OH}$ mole ratio) 1.4. The reactants were weighed in a small glass beaker, stirred well at $70^{\circ} \mathrm{C}$ and degassed under reduced pressure (2-5 $\mathrm{mm}$ of mercury). The reaction mixture was then<smiles>[R]c1cccc(O)c1</smiles>

Novolac resin

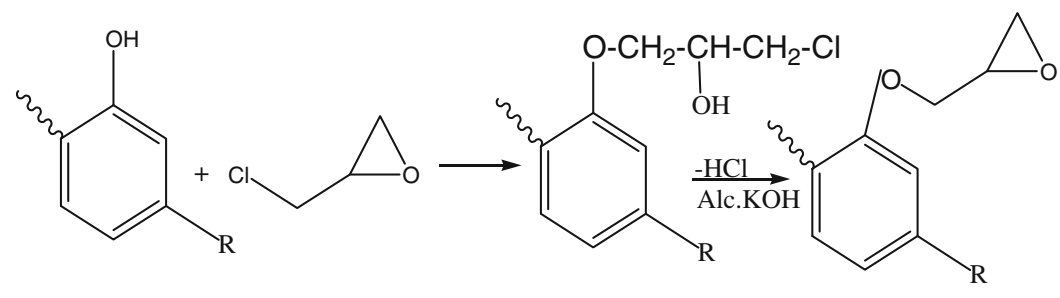

Novolac resin Epichlorohydrin Epoxidized resin<smiles>[R]c1ccc(C)c(OCC2CO2)c1</smiles>

Scheme 1. Formation of synthesized polyol. 


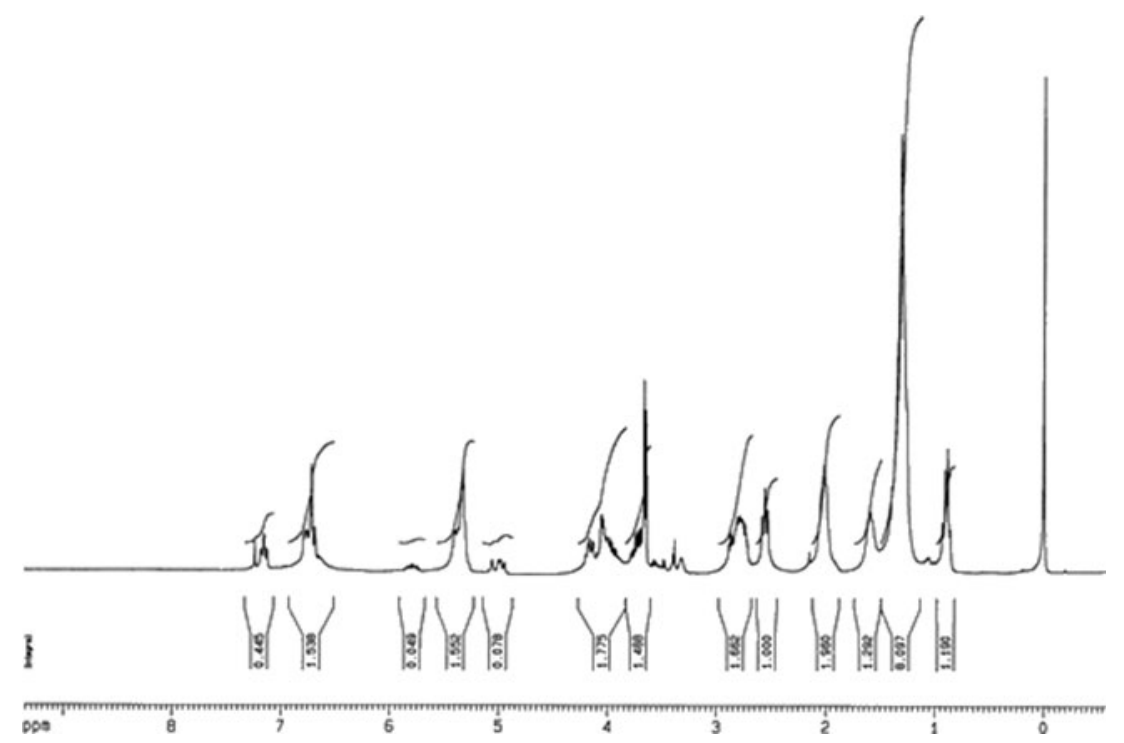

Figure 1. ${ }^{1} \mathrm{H}-\mathrm{NMR}$ spectrum of synthesized polyol.

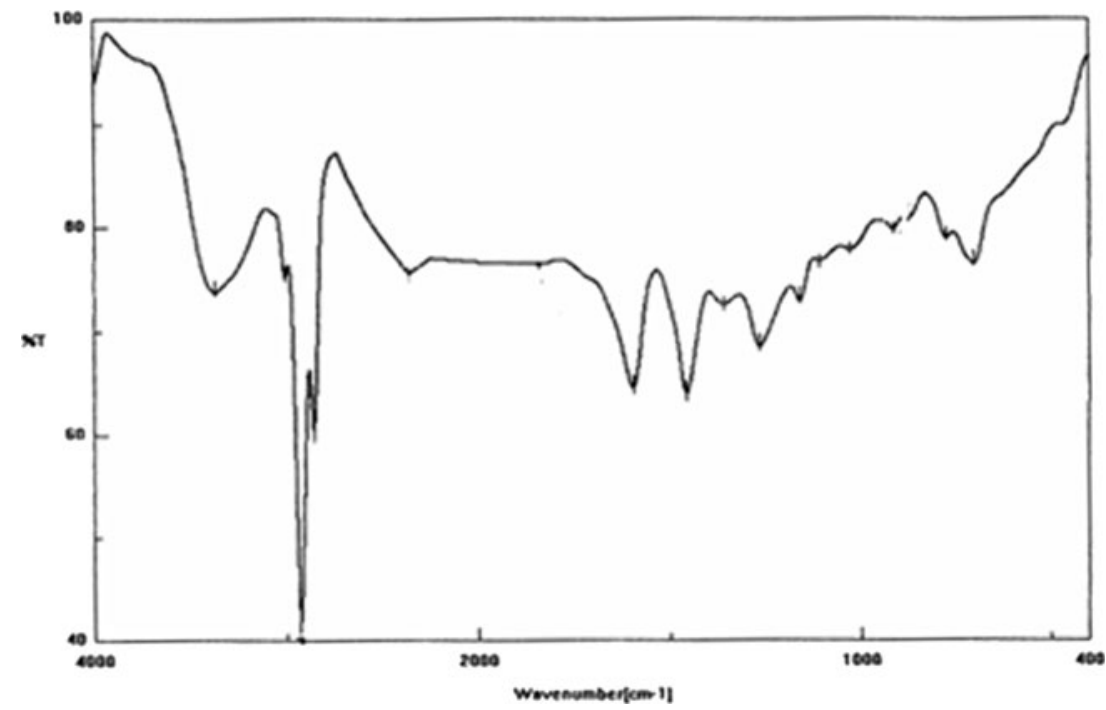

Figure 2. IR spectrum of synthesized polyol.

poured into a flat iron mould and allowed to stand for $24 \mathrm{~h}$ for curing. The samples in the form of sheets of about 1-2 mm thickness were demoulded and finally cured in a vacuum oven at $80^{\circ} \mathrm{C}$ for $48 \mathrm{~h}$. The polyurethane elastomers (PU-PP and PU-PP 2 ) based on commercial polyols; PPG-1200 and PPG-2000 were synthesized by blending the cardanol-based polyol with required quantities of PPG-1200 (weight $\%=$ 23.9) and PPG-2000 (weight $\%=34.4$ ), respectively along with the same diisocyanate and the catalyst by adopting similar experimental procedure as discussed for the synthesis for PU-CP.

\subsection{Static contact angle (SCA) measurement}

Contact angle provides information on the surface hydrophilicity/hydrophobicity and molecular mobility at the air-solid-water interface (Andrade et al 1985). The static contact angles of synthesized polyurethane were measured using Rame Hart goniometer (Model 100-00-230). Static contact angle measurement analysis was performed by depositing $1 \mathrm{ml}$ droplets of de-ionized water onto the surface of polyurethane sheet and taking photos through a magnifying lens using a digital camera. This process was repeated 8-10 times for each sample. The height, $h$ and the length, $l$ of the droplet were measured and the static contact angle between the droplet and the coated surface calculated using the equation, $\tan (\theta / 2)=2 \mathrm{~h} / \mathrm{l}$, where $\theta$ is the static contact angle in degrees.

\subsection{Swelling experiments}

Equilibrium swelling experiments were performed at $30^{\circ} \mathrm{C}$ to determine solubility parameter of polyurethane samples. 
In the swelling experiments, a so-called pat and weight technique was used for liquid sorption (David and Staley 1974). Samples, after taking the dry weight, were placed in dimethyl acetamide in a standard joint test tube, which was maintained at a temperature of $30^{\circ} \mathrm{C}$. The specimens were taken out at regular intervals and solvents adhering to the surface was rubbed off, weighed immediately, and replaced in solvent. This was repeated for three specimens from each network in order to ensure the reproducibility of the values. The time taken for wiping out the solvent from the sample surface was kept to a minimum in order to minimize error due to solvent evaporation. The swelling coefficient, $Q$ was calculated using the formula,

$$
Q=\frac{\text { Weight of solvent in swelled polymer } \times d_{\mathrm{s}}}{\text { Weight of the polymer subjected to swelling } \times d_{\mathrm{r}}}
$$

where $d_{\mathrm{s}}$ is the density of solvent and $d_{\mathrm{r}}$ the density of polymer.

The solubility parameters of solvents were plotted against the swelling coefficient of the polyurethanes. The peak of the curve gives the solubility parameter of the polyurethanes. The densities of polymer films were determined by a floatation method. The crosslink density was determined using modified Flory-Rehner equation (Flory and Rehner 1943)

$$
\gamma=\frac{V_{\mathrm{r}}+\chi V_{\mathrm{r}}^{2}+\ln \left(1-V_{\mathrm{r}}\right)}{d_{\mathrm{r}} V_{\mathrm{o}}\left(V_{\mathrm{r}}^{1 / 3}-V_{\mathrm{r}} / 2\right)}=\frac{1}{M_{\mathrm{c}}},
$$

where $V_{\mathrm{r}}$ is the volume fraction of polyurethane in swollen polymer, i.e. $V_{\mathrm{r}}=1 / 1+Q, Q$ the swelling coefficient, $V_{\mathrm{o}}$ the molar volume of the solvent, $M_{\mathrm{c}}$ the molecular weight between two cross links, $d_{\mathrm{r}}$ the density of polyurethane.

Polymer-solvent interaction parameter, $\chi$ which was calculated using the equation (Hiaw et al 1990)

$$
\chi=\frac{\beta+V_{\mathrm{s}}\left(\delta_{\mathrm{s}}-\delta_{\mathrm{p}}\right)^{2}}{R T},
$$

where $V_{\mathrm{s}}$ is the molar volume of solvent, $R$ the gas constant, $\delta_{\mathrm{s}}$ the solubility parameter of DMA, $\delta_{\mathrm{p}}$ the solubility parameter of polyurethane, $T$ the absolute temperature, $\beta$ the lattice constant which is generally taken as 0.34 for good solvent.
When $\delta_{\mathrm{s}}=\delta_{\mathrm{p}}$, the polymer-solvent interaction parameter $(\chi)$ becomes equal to the lattice constant $(\beta)$. Using solvent interaction parameter $(\chi)$, the crosslink density of the polyurethanes was determined.

\subsection{Mechanical testing}

Cured polyurethane samples were kept in the vacuum oven overnight. According to ASTM -D 412 specifications, dumbbell specimens were cut out from polyurethane sheets and the tensile strength, percentage elongation and modulus were determined using universal tensile testing machine. Indentation hardness (Shore A hardness) of all the samples was measured by means of a type A Shore durometer at room temperature as per ASTM-A 2240.

\subsection{Thermal properties}

The thermal properties of the polyurethanes were studied by differential thermal analysis (DTA) and thermo-gravimetric analysis (TGA) at a rate of $20^{\circ} \mathrm{C} / \mathrm{min}$ in nitrogen using Universal V4.3A Instruments.

\section{Results and discussion}

Polyurethanes prepared by a transfer molding technique were in the form of thin amber coloured sheets. Polyurethane prepared from synthesized polyol (PU-CP) was hard and rigid, PU-1 was soft and the PPG-2000 based polyurethane $\left(\mathrm{PU}-\mathrm{PP}_{2}\right)$ was found to be soft and sticky.

\subsection{Static contact angle}

Surface hydrophilicity of polyurethane sheets is very important for water selectivity. Contact angle decreased with increasing length of PPG soft segment. A higher contact angle value represents a more hydrophobic surface (Owens and Wendts 1969). PU-CP showed higher contact angle value and $\mathrm{PU}-\mathrm{PP}_{2}$ showed the lowest contact angle value (table 1).The reason for the low contact angle value of PU$\mathrm{PP}_{2}$ is attributed to the presence of long flexible hydrophilic

\begin{tabular}{|c|c|c|c|c|c|c|}
\hline $\begin{array}{l}\text { Polyurethane } \\
\text { code }\end{array}$ & $\begin{array}{l}\text { Density } \\
(\mathrm{g} / \mathrm{cc})\end{array}$ & $\begin{array}{l}\text { Swelling } \\
\text { coefficient } \\
\text { in DMA } \\
(Q)\end{array}$ & $\begin{array}{c}\text { Volume } \\
\text { fraction of } \\
\text { polyurethane } \\
\left(V_{\mathrm{r}}\right)\end{array}$ & $\begin{array}{l}\text { Cross link } \\
\text { density } \\
\times 10^{-3}\end{array}$ & $\begin{array}{c}\text { Molecular weight } \\
\text { between } \\
\text { cross-links } \\
\left(\text { mole }^{-1}\right)\end{array}$ & $\begin{array}{c}\text { Contact } \\
\text { angle }\end{array}$ \\
\hline PU-CP & $1 \cdot 11$ & $1 \cdot 28$ & 0.439 & 0.979 & $738 \cdot 72$ & $70^{\circ}$ \\
\hline PU-PP 1 & 1.08 & 1.43 & 0.412 & 0.965 & $811 \cdot 82$ & $66^{\circ}$ \\
\hline PU-PP 2 & 1.04 & $1 \cdot 50$ & 0.400 & 0.955 & 883.74 & $62^{\circ}$ \\
\hline
\end{tabular}
soft segment containing large number of $-\mathrm{OH}$ groups.

Table 1. Physical parameters of polyurethanes. 


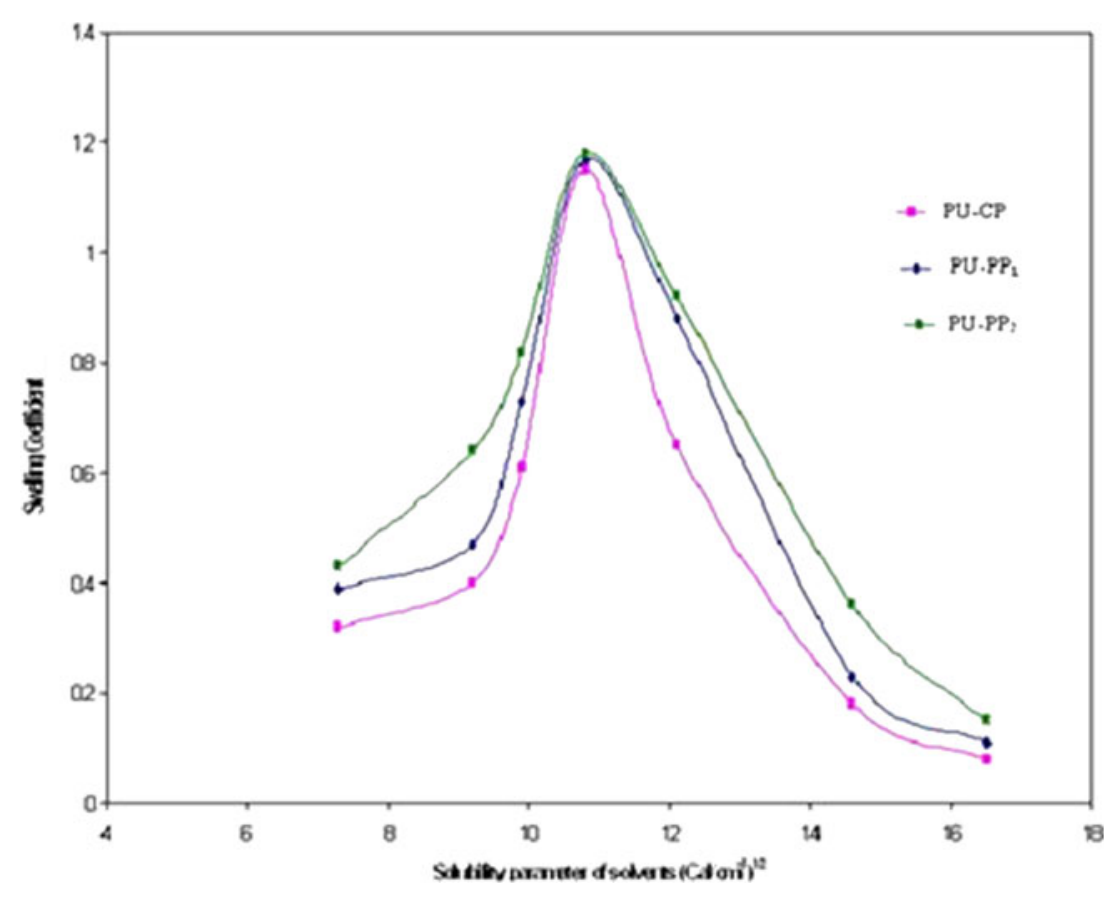

Figure 3. Swelling coefficient curves of polyurethanes.

\subsection{Swelling characteristics and crosslink density}

The swelling measurements of the polyurethanes were carried out in various solvents with different solubility parameter values $(\delta)$ ranging from $7 \cdot 3$ to $16 \cdot 5\left(\mathrm{cal} / \mathrm{cm}^{3}\right)^{1 / 2}$. When the solubility parameters of solvents were plotted against the swelling coefficient of the polyurethanes, a maximum in the peak corresponding to the solubility parameter of dimethyl acetamide was obtained (figure 3). Among all the solvents used, the solubility parameter of dimethyl acetamide $\left(\delta_{\mathrm{s}}\right)$ was found to be the solubility parameter of polyurethanes, as there was maximum swelling only in this solvent. The swelling properties of these polyurethanes reveal that the present polyurethanes are cross-linked. These cross-linked polymers will only swell and do not dissolve in a non-reactive solvent. The degree of swelling in a nonreactive solvent determines the degree of cross-linking and hence the molecular weight between cross links $\left(M_{\mathrm{c}}\right)$. Higher the $M_{\mathrm{c}}$, lower will be the cross-link density.

In the present investigation, the cross-link density of PU$\mathrm{CP}$ was found to be higher when compared with those prepared with the addition of commercial polyols, PPG-1200 and PPG-2000 (table 1). Accordingly, the molecular weight between crosslinks, $M_{\mathrm{c}}$ was also found to be minimum in this case. The low cross-link density of commercial polyoladded polyurethanes may be due to the steric hindrance of the pendant methyl groups of polypropylene glycol. From table 1 it was observed that among these three polyurethanes, the synthesized polyol-based polyurethane (PU-CP) possesses higher cross-link density than those of PPG-based polyurethanes $\left(\mathrm{PU}-\mathrm{PP}_{1}\right.$ and $\left.\mathrm{PU}-\mathrm{PP}_{2}\right)$. It was reported that, as the distance between two cross-link points increases with an increase in chain length (for a given $\mathrm{NCO} / \mathrm{OH}$ ratio) of highly flexible PPG, the free volume available also increases and hence the volume fraction of polyurethane $\left(V_{\mathrm{r}}\right)$ in swollen polymer decreases (Bharadwaj et al 2002). The increase in chain length increases the distance between two cross-link points resulting in a less dense cross-linked structure. Therefore $M_{\mathrm{c}}$ increases with the increase in molecular weight of PPG-incorporated polyurethane network.

\subsection{Mechanical properties}

The tensile properties in terms of tensile strength, modulus and percentage elongation evaluated from stress-strain curves are tabulated in table 2 . The data show a gradual decrease in all mechanical properties from PU-CP to PU$\mathrm{PP}_{2}$. In the case of higher molecular weight polyol-based polyurethane $\mathrm{PU}-\mathrm{PP}_{2}$, there is an unequal distribution of load throughout the network due to its low cross-link density and due to the presence of longer chain length of the

Table 2. Mechanical properties of polyurethanes.

\begin{tabular}{lcccc}
\hline $\begin{array}{l}\text { Polyurethane } \\
\text { code }\end{array}$ & $\begin{array}{c}\text { Shore A } \\
\text { hardness }\end{array}$ & $\begin{array}{c}\text { Tensile } \\
\text { strength } \\
(\mathrm{MPa})\end{array}$ & $\begin{array}{c}\text { Elongation } \\
(\%)\end{array}$ & $\begin{array}{c}\text { Tensile } \\
\text { modulus } \\
(\mathrm{MPa})\end{array}$ \\
\hline PU-CP & 90 & $\mathrm{~B}$ & $\mathrm{~B}$ & $\mathrm{~B}$ \\
PU-PP & 80 & $30 \cdot 1$ & 139 & $21 \cdot 7$ \\
PU-PP & 60 & $25 \cdot 0$ & 154 & $16 \cdot 2$ \\
\hline
\end{tabular}

B, Brittle. 


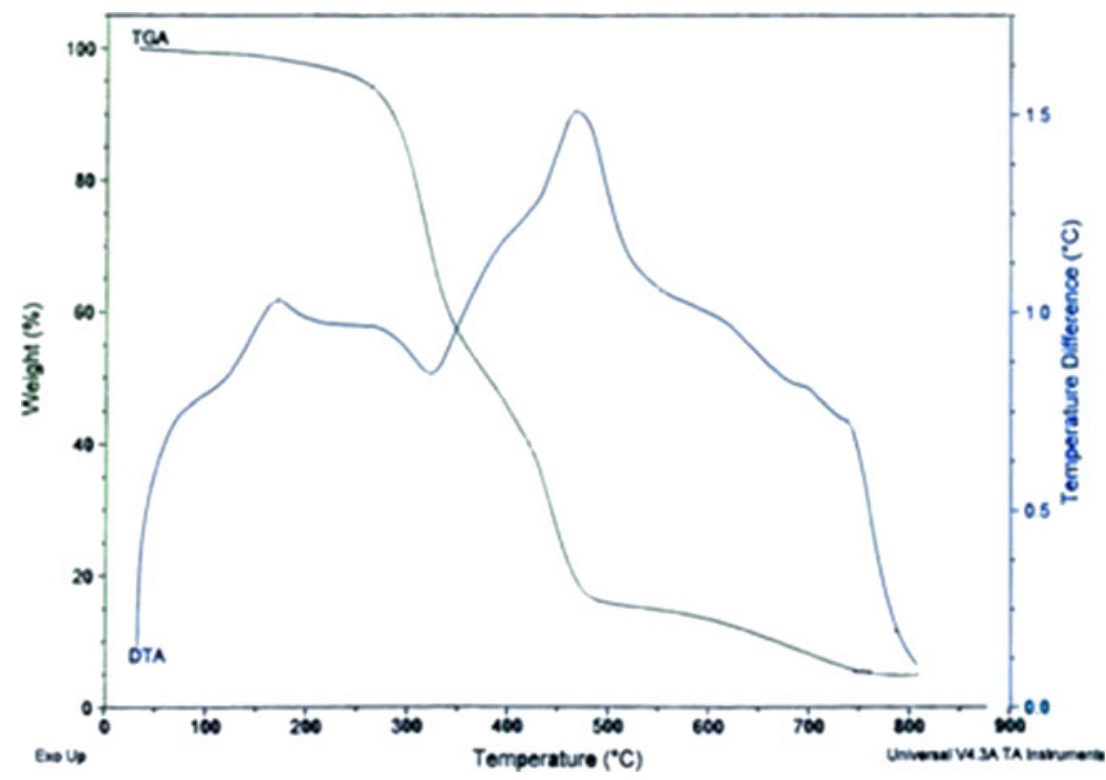

Figure 4. TGA and DTA curves of PU-CP.

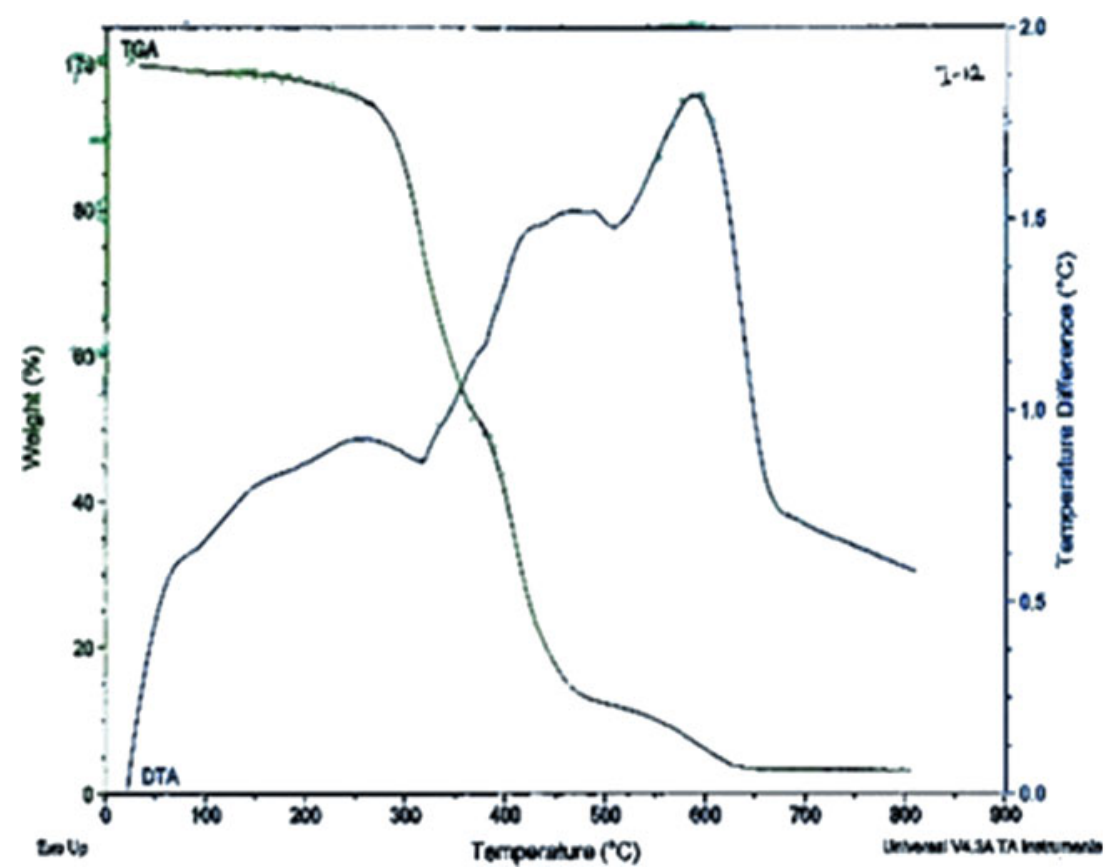

Figure 5. TGA and DTA curves of PU-PP 1 .

soft segment PPG-2000. When the load is applied to the polymer network of PU-PP ${ }_{2}$, because of its high flexibility, it throws away the load to the rigid part of the network and creates stress concentration at that region. Ultimately, rupture takes place even at low load, resulting in a decrease in tensile strength. However, in the case of PU-CP and PU-PP ${ }_{1}$, the shorter length of flexible chain contributes to bare load along with the rigid hard segment region coordinately, which leads to an increase in tensile properties.

Hardness of polyurethane samples is also shown in table 2 . As seen from the table, hardness of polyurethane increases with a decrease in the chain length of PPG. This is due to the fact that as chain length is decreased, cross-link density increases, which results into more rigid network with better mechanical properties.

\subsection{Thermal properties}

Thermograms of polyurethane samples are shown in figures 4-6 and the DTA and TGA analysis data of polyurethanes are presented in tables 3 and 4, respectively. The nature of the 


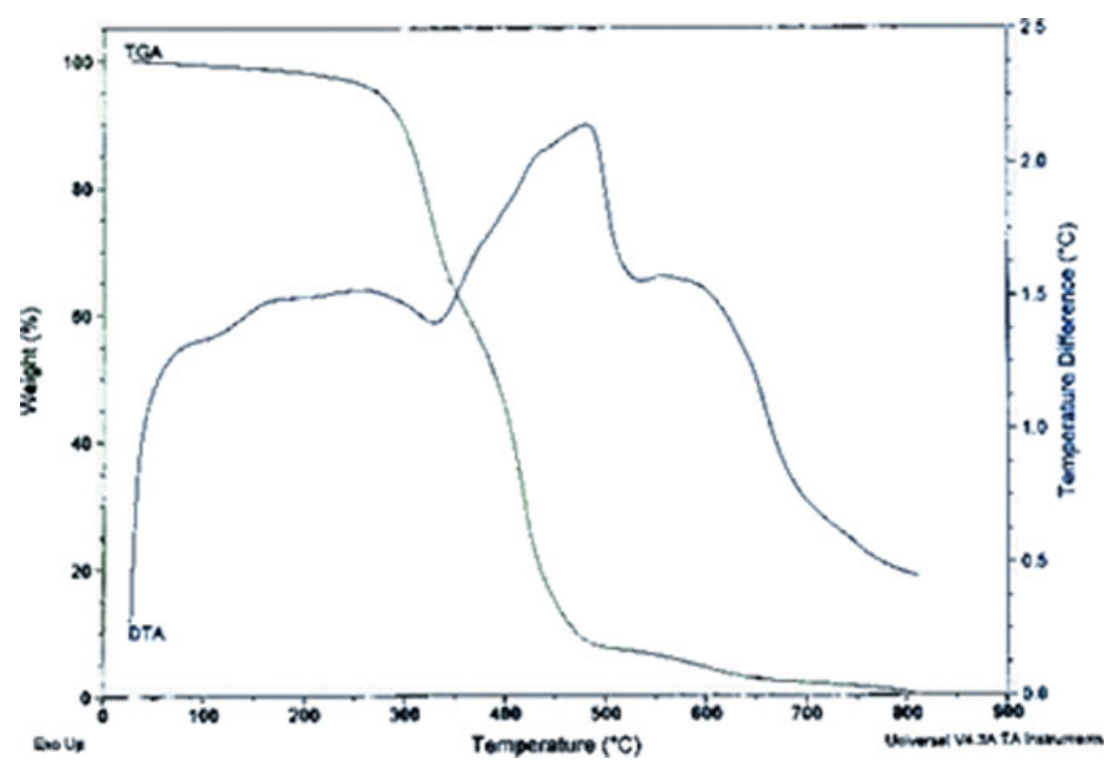

Figure 6. TGA and DTA curves of $\mathrm{PU}-\mathrm{PP}_{2}$.

thermograms of all the polyurethanes were found to be similar, showing two step decomposition. The DTA curves of polyurethanes do not show any endothermic peak for softening. But two or three exotherms are invariably seen in all the cured polyurethanes. The first exotherm is relatively weak and the second exotherm is strong in all the three polyurethanes. The first exotherm is due to the cleavage of meta-substituted long alkyl side chain of the phenyl ring and also due to the cleavage of allophanate linkages.

The last exotherm of $\mathrm{PU}-\mathrm{CP}$ occurs at higher temperature $\left(739^{\circ} \mathrm{C}\right)$ than those of other two polyurethanes $\mathrm{PU}-\mathrm{PP}_{1}$ and $\mathrm{PU}-\mathrm{PP}_{2}$ which occurs at $588^{\circ} \mathrm{C}$ and $557^{\circ} \mathrm{C}$, respectively. As can be seen from the TGA thermograms, all the polyurethane samples, regardless of the chain length of polyol used,

Table 3. Differential thermal analysis data of polyurethanes.

\begin{tabular}{lccc}
\hline & \multicolumn{3}{c}{ Exotherm $\left({ }^{\circ} \mathrm{C}\right)$} \\
\cline { 2 - 4 } Polyurethane code & First & Second & Third \\
\hline PU-CP & 172 & 467 & 739 \\
PU-PP 1 & 253 & 450 & 588 \\
PU-PP & 254 & 481 & 557 \\
\hline
\end{tabular}

undergo spontaneous decomposition around $270^{\circ} \mathrm{C}$. Once the degradation has started, weight loss is rapid. The initial weight loss (about $5 \%$ ) up to $200^{\circ} \mathrm{C}$ is attributed to the moisture retained in the sample. The PU-CP decomposes around $79 \%$ at $500^{\circ} \mathrm{C}$, whereas the polyurethanes PU-PP and PU-PP ${ }_{2}$ decompose around $84 \%$ and $86 \%$, respectively at the same temperature.

The first break of the TG curves around $270^{\circ} \mathrm{C}$ is due to the de-cross-linking or post-curing process. The second break at around $380-500^{\circ} \mathrm{C}$ indicates the decomposition of polyurethane moiety of the compound. And the last break occurs at above $520^{\circ} \mathrm{C}$ is due to disintegration of the resin moiety into simpler molecules. The typical char is a carbonaceous material that forms during thermal degradation. It was reported that (Lyon 1998), char yield as determined from TGA experiments are an indirect way of measuring the fire retardant property or in other words thermal stability. Thus greater the char residue percentage, higher will be the thermal stability. The percentage of char residue decreases from PU-CP to PU-PP ${ }_{2}$ thereby showing the higher thermal stability of PU-CP which has the higher cross-link density when compared to the other two polyurethanes PU-PP ${ }_{1}$ and PU-PP 2 .

The activation energy $\left(E_{\mathrm{a}}\right)$, which is a quantitative measure of thermal stability, associated with each stage of

Table 4. Thermogravimetric analysis data of polyurethanes.

\begin{tabular}{lcccccc}
\hline & \multicolumn{4}{c}{ Weight loss at various temperatures (\%) } & & Char residue (\%) \\
\cline { 2 - 5 } $\begin{array}{l}\text { Polyurethane } \\
\text { code }\end{array}$ & $100{ }^{\circ} \mathrm{C}$ & $200{ }^{\circ} \mathrm{C}$ & $300{ }^{\circ} \mathrm{C}$ & $400{ }^{\circ} \mathrm{C}$ & $500{ }^{\circ} \mathrm{C}$ & $800{ }^{\circ} \mathrm{C}$ \\
\hline PU-CP & 0 & $0 \cdot 5$ & 15 & 35 & 79 & 4.91 \\
PU-PP 1 & 0 & 3 & 15 & 44 & 84 & $3 \cdot 20$ \\
PU-PP $_{2}$ & 0 & 2 & 15 & 31 & 86 & $0 \cdot 26$ \\
\hline
\end{tabular}




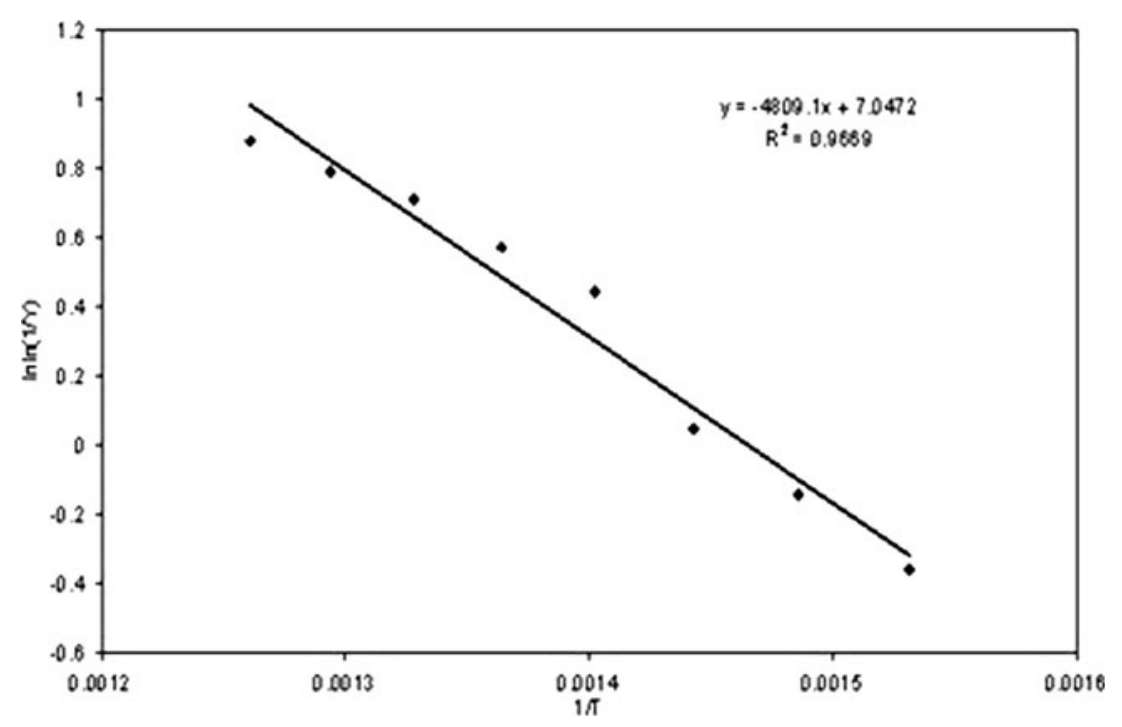

Figure 7. Representative Broido plot of $\mathrm{PU}-\mathrm{PP}_{1}$.

decomposition of the polymers was calculated from TGA analysis using the well-known Broido method (Broido 1969) given by the expression,

$$
\ln [\ln 1 / Y]=\frac{-E_{\mathrm{a}}}{R T}+\text { constant, }
$$

where

$$
Y=\frac{\left(W_{\mathrm{t}}-W_{\infty}\right)}{\left(W_{0}-W_{\infty}\right)}
$$

where $Y$ is the fraction of the initial number of initial molecules not yet decomposed; $W_{\mathrm{t}}$ the weight at anytime $t$; $W_{\infty}$ the weight at infinite time (= zero) and $W_{0}$ the initial weight of the sample. A plot of $\ln [\ln (1 / Y)]$ vs $1 / T$ gives an excellent approximation to a straight line. Representative plot for $\mathrm{PU}_{-\mathrm{PP}}{ }_{1}$ is shown in figure 7. Regression analysis was carried out for the Broido plots. The regression analysis gives the results of slopes, constants and $R^{2}$ values corresponding to each step of thermal degradation. The regression coefficient $\left(R^{2}\right)$ and calculated activation energy $\left(E_{\mathrm{a}}\right)$ for each step of thermal degradation process are tabulated in table 5. The activation energy values presented in the table

Table 5. Kinetic parameters for the thermal degradation of polyurethanes.

\begin{tabular}{lccc}
\hline $\begin{array}{l}\text { Polyurethane } \\
\text { code }\end{array}$ & $\begin{array}{c}\text { Decomposition } \\
\text { temperature } \\
\text { range }\left({ }^{\circ} \mathrm{C}\right)\end{array}$ & $R^{2}$ & $\begin{array}{c}\text { Activation } \\
\text { energy } \\
\mathrm{kJ} / \mathrm{mol}\end{array}$ \\
\hline PU-CP & $260-350$ & 0.9974 & $70 \cdot 0$ \\
& $380-500$ & 0.8884 & $42 \cdot 7$ \\
PU-PP 1 & $260-360$ & 0.9547 & $67 \cdot 1$ \\
& $380-520$ & 0.9669 & 40.0 \\
PU-PP 2 & $250-340$ & 0.9883 & 59.4 \\
& $360-520$ & 0.9102 & 39.7 \\
\hline
\end{tabular}

suggest that, the energy of activation $\left(E_{\mathrm{a}}\right)$ is higher for the first stage than the second stage of degradation in all the polyurethanes and it could be predicted that the second step of degradation is the fastest step. Of all the polyurethanes, $\mathrm{PU}-\mathrm{CP}$ is found to possess higher activation energy. This is attributed to the high cross-link density of PU-CP. So energy needed to break the rigid 3-D structure is high when compared to $\mathrm{PU}-\mathrm{PP}_{1}$ and $\mathrm{PU}-\mathrm{PP}_{2}$. Thus, it is concluded that $\mathrm{PU}-\mathrm{CP}$ is thermally more stable than PU-PP ${ }_{1}$ and $\mathrm{PU}-\mathrm{PP}_{2}$.

\section{Conclusions}

Polyurethane elastomers synthesized from cardanol-based polyol and linear polypropylene glycols (PPGs) were thin sheets showing rigid to tough characteristic behaviour depending on the nature and molecular weight of the polyols. Sorption coefficients were found to be dependent on the cross-link density and structure of the network. The thermal stability of the polyurethane elastomers are found to decrease in the order of PU-CP $>$ PU-PP $1>$ PU-PP ${ }_{2}$, while PU-PP exhibited best mechanical properties. Thus it is concluded that $\mathrm{PU}-\mathrm{PP}_{1}$ with optimum mechanical properties and high thermal stability can be widely used in biomedical field.

\section{References}

Bastids S 1995 J. Appl. Polym. Sci. 561487

Bharadwaj V, Somani K and Kamsara S 2002 J. Macromol. Sci. Pure A39 115

Broido A 1969 J. Polym. Sci. Part A-2. Polym. Phys. 71761

Buist J M 1978 Development in polyurethane-1 (London: Applied Science Publishers Ltd)

David D J and Staley H B 1974 In analytical chemistry of polyurethanes, Part III: high polymers, Vol. XVI, p. 365

Desai S, Thakore I M and Devi S 1998 Polym. Int. 47172

Flory P J and Rhener J 1943 J. Chem. Phys. 11521 
Hiaw H, Ping Z H, Xie J W and Yu T Y 1990 J. Polym. Sci., Part A: Polym. Chem. 28585

Javni I, Petrovic Z S, Guo A and Fuller R J 2000 Appl. Polym. Sci. 771723

Klaus Friedrich, Stoyko Fakirov and Zhong Zhang 2005 Polymer composites from nano- to macro-scale (Springer Science+Business Media, Inc)

Kumar P P, Paramashivappa P J, Vithayathil J, Subra Rao P V and Srinivasa Rao A 2002 J. Agric. Food Chem. 504705

Lin I S and Biranowski Lorenz D H 1981 Urethane chemistry and applications (ed.) K N Edwards (ACS Symposium Series 172), Ch. 34, p. 523
Mythili C V, Malar Retna A and Gopalakrishnan S 2004 Bull. Mater. Sci. 27235

Rajalingan S and Radhakrishnan G 1995 Polym. Int. 2587

Ramesh S, Rajalingam P and Radhakrishnan G 1991 Polym. Int. 25 253

Saminathan M and Pillai C K S 2000 Polymer 413103

Sathiyalekshmi K and Gopalakrishnan S 2000 Plast. Rubber Compos. 2963

Saunders J H and Frisch K C 1962 Polyurethanes chemistry and technology, Part 1. chemistry (New York: Interscience Publishers)

Szycher M 1999 Szycher's handbook of polyurethanes (Boca Raton, Washington D.C.: CRC Press) 